\title{
The State of the Science and Technology in Deep Borehole Disposal of Nuclear Waste
}

\author{
Dirk Mallants ${ }^{1, *(\mathbb{D})}$, Karl Travis ${ }^{2} \mathbb{D}$, Neil Chapman ${ }^{3}$, Patrick V. Brady ${ }^{4}$ and Hefin Griffiths ${ }^{5}$ \\ 1 Commonwealth Scientific and Industrial Research Organisation Land and Water, Waite Road-Gate 4, Glen \\ Osmond, SA 5064, Australia \\ 2 Department of Materials Science and Engineering, Sheffield University, Sheffield S1 3JD, UK; \\ k.travis@sheffield.ac.uk \\ 3 Chapman \& Co. Consulting, Remigen, Switzerland and Department of Materials Science and Engineering, \\ Sheffield University, Sheffield S1 3JD, UK; neil.chapman@arius-world.org \\ 4 Advanced Nuclear Energy Programs, SANDIA National Laboratories, Albuquerque, NM 87123, USA; \\ pvbrady@sandia.gov \\ 5 Australian Nuclear Science and Technology Organisation, New Illawarra Rd, Lucas Heights, NSW 2234, \\ Australia; hwg@ansto.gov.au \\ * Correspondence: dirk.mallants@csiro.au
}

Received: 13 January 2020; Accepted: 11 February 2020; Published: 14 February 2020

check for updates

\begin{abstract}
This Special Issue of the Energies Journal on Deep Borehole Disposal of Nuclear Waste has delivered a timely update on the science and technology of borehole disposal and the types of radioactive wastes it could potentially accommodate. The Special Issue papers discuss (i) circumstances under which a national waste management programme might wish to consider deep borehole disposal; (ii) a status report of deep borehole disposal options in Germany; (iii) the analysis of corrosion performance of engineered barrier systems; (iv) a review of the potential cementing systems suitable for deep borehole disposal; ( $v$ ) the thermal evolution around heat-generating waste for a wide range of material properties and disposal configurations; (vi) a geochemical analysis of deep brines focussed on fluid-rock interactions; (vii) post-closure performance assessment calculations for deep borehole disposal of Cs/Sr capsules and an example safety case for (viii) horizontal and (ix) vertical deep borehole disposal of nuclear wastes.
\end{abstract}

Keywords: deep boreholes; nuclear waste disposal; state of the science and technology

\section{Introduction}

The management of radioactive wastes from medical, scientific and industrial uses of radio-isotopes and from energy production poses both technological and societal challenges. Low-level and some intermediate-level radioactive wastes (LILW) might be safely disposed of in engineered near-surface repositories, but longer-lived intermediate-level waste (ILW), spent fuel from nuclear reactors (SF), high-level wastes from the reprocessing of SF (HLW) and long-lived spent sealed sources (SSS) are considerably more radioactive and have a higher content of long-lived radionuclides. These wastes require a higher degree of containment and isolation deep underground, typically in geological disposal facilities (GDF). A wide range of GDF designs have been investigated and developed internationally, tailored to suit specific waste types and geological conditions. Disposal in medium-depth (tens to hundreds of metres) boreholes in suitable hard rock or sedimentary formations is considered to provide adequate isolation and containment for the safe and cost-effective disposal of relatively small volumes of ILW and SSS. Deeper borehole disposals (hundreds to thousands of metres) have been considered for HLW, SF, separated plutonium wastes and some very high specific activity fission-product wastes-its modularity being one of the major advantages over traditionally mined GDFs [1]. 
An overview of the Research, Development and Demonstration (RD\&D) work on medium-depth SSS disposal and deep borehole disposal for various nuclear wastes over the past decade was recently published in a Special Issue of The Energies Journal. It comprised nine papers on the following topics:

- Waste types, including waste types suitable for deep borehole disposal and the circumstances under which a national waste management programme might wish to consider deep borehole disposal [1], and the status of deep boreholes as a potential option for disposal of high-level waste in Germany [2];

- Engineered barrier performances, including corrosion performances of engineered barrier systems [3] and potential cementing systems suitable for deep borehole disposal [4];

- Performance assessments, including the thermal evolution around heat-generating waste for a wide range of material properties and disposal configurations [5], geochemical analyses of deep brines focussed on fluid-rock interactions [6] and post-closure performance assessment calculations for the deep borehole disposal of Cs/Sr capsules [7] and

- Safety cases, including deep horizontal drill-holes in sedimentary, metamorphic or igneous rocks [8] and safety case aspects for deep vertical boreholes [9].

We summarise the main findings in this paper.

\section{Special Issue Summary}

\subsection{Waste Types}

The first paper assumes that deep borehole disposal can be implemented safely and effectively and is therefore a realistic disposal option. Demonstrating safety to the standard required for conventional geological disposal facilities is believed to be achievable with adequate resources [1]. The borehole concept adopted has a bottom hole internal diameter of around 300-450 $\mathrm{mm}$, a drill depth of two to three kilometres (and possibly up to five or six kilometres) and several multiple-seal systems. A high degree of isolation and containment is posited due to density stratification from high salinity groundwater or fluids and low hydraulic gradients at these depths. For waste types to be suitable for deep borehole disposal, their attributes should be: (i) small total volume, (ii) small package size, (iii) high specific activity, (iv) high concentration of long-lived radionuclides and (v) contain separated fissile materials. A large total volume or large package sizes potentially render the waste unsuitable for deep borehole disposal. The disposal of several hundreds to a thousand $\mathrm{m}^{3}$ of vitrified high-level waste in several deep boreholes with at least two $\mathrm{km}$ disposal zones seems feasible. A couple of boreholes would also suffice for small volume inventories of spent nuclear fuel elements, which require smaller diameter boreholes. A modest nuclear power programme requires several tens of boreholes, while for a large nuclear power programme, several hundreds of boreholes are needed. The author also considers several niche applications for deep boreholes, such as for very high activity ${ }^{137} \mathrm{Cs} /{ }^{90} \mathrm{Sr}$ sources in small capsules and separated fissile material (e.g., ${ }^{239} \mathrm{Pu}$ ) that would be much less accessible (i.e., recoverable) in a deep borehole than a geological repository, and therefore, better satisfy safeguards requirements. In addition to technical considerations, opting for borehole disposal could also reflect strategic and political considerations: (i) to remove a problematic waste stream from disposal in a geological repository (e.g., high burn-up MOX fuels), (ii) to achieve early disposal, (iii) more economic for smaller waste volumes and/or (iv) no other available solution (e.g., geological repository). For large volumes of waste requiring disposal or the need for retrievability (a fully sealed and decommissioned borehole makes retrievability practically impossible), a borehole solution may be less suitable. The paper argues that the same societal issues will emerge for siting boreholes as for siting a geological repository. A borehole suitability categorisation for national waste inventories is presented: for nations with a small nuclear power programme without reprocessing or with no nuclear power programme but with research reactors and other nuclear $\mathrm{R} \& \mathrm{D}$ waste, deep borehole disposal seems most promising; for countries with a small-to-medium nuclear power programme with reprocessing, borehole disposal 
might be suitable for small volumes of vitrified high-level waste and for countries with large volumes of spent fuel, deep boreholes are less attractive, unless for specific complex waste types. The paper closes with a call for action: demonstration of the deep borehole concept, including several iterations of operational and post-closure safety cases and positive regulatory feedback around these safety cases, and a comparative economic analysis between borehole disposal and geological repositories [1].

A second paper discusses the potential of deep boreholes for the disposal of Germany's vitrified high-level waste [2]. Germany was identified in [1], together with Italy, Japan and the Netherlands, as having a medium-to-large nuclear power programme with access to reprocessing, and therefore, likely to develop a national geological repository for all their high-level waste; deep borehole disposal could be considered if small volumes of high-level waste existed. Currently, the German government is monitoring scientific, technical and other developments in deep borehole disposal around the globe ahead of any strategic commitment [2]. The paper identifies 11 geoscientific siting requirements for HLW disposal and considers most are achievable with a deep borehole disposal concept, although there could be challenges in characterising the rock and maintaining temperatures below $100{ }^{\circ} \mathrm{C}$ at the outer surface of disposal containers at the disposal depth. A deep borehole disposal concept to accommodate Germany's high-level waste inventory of approximately $7600 \mathrm{~m}^{3}$ of spent fuel rods, $2000 \mathrm{~m}^{3}$ of vitrified waste canisters from spent fuel reprocessing and $2000 \mathrm{~m}^{3}$ of spent fuel elements from research reactors (including pebbles) is then discussed. The authors present a novel 5.6-m-long disposal container that can accommodate all three high-level waste types, provided a sufficiently wide borehole can be drilled. Holes up to $44.5 \mathrm{~cm}$ in diameter can only accommodate a disposal container with spent fuel elements ( $26.5 \mathrm{~cm}$ outer diameter), while $75-\mathrm{cm}$-diameter holes can accommodate containers for all waste types ( $52.5 \mathrm{~cm}$ outer diameter). While the smaller diameter holes can be drilled with off-the-shelf equipment, the larger holes would require the further development and testing of drilling equipment. For deep borehole disposal to proceed in Germany, developing a feasibility test for larger boreholes and changes to legislation would be required.

\subsection{Engineered Barrier Performance}

In the concept of deep borehole disposal, less reliance is placed on engineered barriers, because at depths of several kilometres, the host rock is assumed to provide greater isolation and containment than for shallower geological repositories. Nevertheless, a minimum level of engineered barriers are considered for both horizontal [3] and vertical [4] boreholes. Two papers focus on the performances of engineered barriers: corrosion-resistant alloys for use in horizontal holes [3] and cementitious materials for sealing and support matrices [4].

The corrosion performances of disposal canisters of nickel-chromium-molybdenum (Ni-Cr-Mo) alloys are discussed for a horizontal disposal concept of high-level waste [3]. General corrosion was studied by dividing the long repository compliance timeframe into several shorter time periods, with typical corrosion rates assigned to each period, which is called the corrosion-period evolution method. Alloy 625 (UNS N06625) was tested using realistic thermal and geochemical boundary conditions for each of the testing periods and corrosion rates that were 100 times higher than typical literature values $(0.01 \mu \mathrm{m} / \mathrm{y})$. Metal loss and the remaining metal thickness for given corrosion rates were calculated. $\mathrm{Fe}_{3} \mathrm{O}_{4}$ was assumed to be the main corrosion product, with hydrogen gas production estimated at 0.2 $\mathrm{mol} / \mathrm{m}^{2} / \mathrm{y}$ (corrosion rate of $1 \mu \mathrm{m} / \mathrm{y}$ ). When corrosion rates were varied to account for time-dependent boundary conditions (temperature and geochemistry), canister perforation was estimated to occur after 40,000 years, when $50 \%$ of the initial metal thickness $(9.5 \mathrm{~mm})$ had corroded. These results reflected an initial hot period (lasting at least 100 years) with temperatures in the engineered barriers between $120-170^{\circ} \mathrm{C}$. A key feature of the Ni-Cr-Mo alloys that contributes to their excellent corrosion performance is the formation of a durable protective passive film from the corrosion products (including $\mathrm{NiO}, \mathrm{Cr}_{2} \mathrm{O}_{3}$ and $\mathrm{Fe}_{3} \mathrm{O}_{4}$ ). This film of about 0.9-mm-thick after 1000 years provides protection against localised pitting, crevice corrosion and stress corrosion cracking. 
Cementitious materials can also provide key safety functions for a deep borehole disposal concept. The next paper reviews potential cementing systems suitable for borehole disposal, where the cementitious materials provide both mechanical supports to protect canisters from the load of overlying canisters and limits the ingress of aggressive fluids that could reduce corrosion performance [4]. Seven cement types were evaluated for borehole disposal applications: Portland cement, calcium sulfoaluminate (CSA)/Belite cement, pozzolanic cements, alkali-activated or geopolymeric systems, calcium aluminate cement systems, phosphate cements, and other cementing systems. The Portland-based oil well cement is used extensively in the oil and gas and geothermal energy industry for well cementing. Class $\mathrm{G}$ and $\mathrm{H}$ (Portland) cements have become the most popular products used in oil and gas and geothermal energy well cementing due to the use of advanced retarders that make them better fit for high-temperature environments (up to $120^{\circ} \mathrm{C}$ ). High-temperature environments require additives that allow proper cement hardening and long-term durability of the hardened cement. Silica flour additive improves strength, and thus, durability, while organic retarders control cement hardening. Two time periods are considered to define the requirements of the cementitious material: a two-year period during which the borehole is open and mechanical strength is crucial, and a much longer post-closure period during which the cement contributes to long-term safety. CSA-type systems have ettringite as the main binder, which becomes unstable at temperatures above $65{ }^{\circ} \mathrm{C}$; they are therefore unsuitable for deep borehole disposal under high temperatures. While pozzolanic materials (siliceous or aluminous phases) react with water and calcium hydroxide to form calcium silica hydrate-like phases, they have been avoided in hydrothermal cementing, because high strength phases such as tobermorite are not formed. Some pozzolanic cements react above $90{ }^{\circ} \mathrm{C}$, making them potentially suitable for applications in deep systems. However, the formation of tobermorite is uncertain; therefore, there is doubt they will perform better than Portland cements. Geopolymer cements are based on the hardening of an amorphous aluminosilicate material using very strong alkaline chemical activators, including sodium or potassium hydroxide. The use of such high concentrations of soluble alkali hydroxides at the bottom of the borehole may prevent hardening. Calcium aluminate cement (CAC) systems, also known as aluminous cement or high-alumina cement, have a high resistance to chemical and acid attacks but low resistance to alkali attacks. Although they are stable under very high temperatures, there is little evidence that these cements have been used in temperature and pressure conditions relevant to deep borehole disposal. Phosphate cements or chemically bonded phosphate ceramics form a hardened paste through an acid-base reaction involving metal cations and soluble phosphate in the presence of water. Some of the phosphate-based cements have been used for geothermal applications; however, there is a lack of documented durability tests of their performance under field conditions. Many other cementing systems have been studied for well applications; however, details are lacking or they are not readily available on the market. The paper then considers additional considerations for the selection of suitable cement systems: proven durability, placement, regulation, availability, financial, engineering and placement and radiation stability. A formulation of Class $\mathrm{G}$ oil well cement, silica flour, water, fluid loss additive and retarding admixture has been proposed as suitable for seal and support matrices within the disposal zone.

\subsection{Performance Assessments}

Performance testing of individual engineered barriers and of multibarrier systems under varying boundary conditions is complex and can only be achieved cost-effectively through simulation modelling. Models that couple thermal, hydraulic, mechanical and chemical processes (THMC-models) are used extensively to assess the performances of geological repositories. Three papers present results from simulating different aspects of a borehole disposal system.

The effect of waste canister spacing and barrier configuration on temperature redistribution in a horizontal disposal hole was investigated in one paper [5]. It was shown that the disposal concept can be designed to keep maximum temperatures below critical limits for both engineered and natural components of the repository. Simulations demonstrated that the layout of a monitoring system can 
be optimised to provide more meaningful data from an in situ heater test to determine the thermal properties of the repository. The heat-generating source in these simulations was capsules containing ${ }^{137} \mathrm{Cs}$ and ${ }^{90} \mathrm{Sr}$ extracted during the chemical processing of defence fuel. Keeping temperatures in the repository below the boiling point averts (i) complex-coupled thermal-hydrological-geochemical processes, especially when a steam phase is involved; (ii) expansion and associated thermal stresses and (iii) undesirable mineralogical alterations of the buffer material and/or host rock and improves the corrosion performance of canister materials. In addition to simulations of the temperature evaluation for a set of reference parameters, the study also includes a local and global sensitivity analysis method and a data-worth analysis. The latter is done to design experiments in which the key parameters affecting maximum temperatures can be determined with sufficient accuracy. Results show that boiling conditions in the backfill material between the canister and the casing can be avoided if the initial heat output of the capsules is less than $360 \mathrm{~W}$ at $1-\mathrm{km}$-depth $\left(40^{\circ} \mathrm{C}\right.$ ambient temperature and $0.61 \mathrm{~m}$ capsule spacing). Sensitivity analyses reveal that the most influential parameters are the heat conductivity of the host rock and the strength of the heat source, while least influential are the metallic elements with a high thermal conductivity and small shell thickness. The data-worth analysis enabled the optimal number and location of temperature sensors and the duration of the in situ heating test to be determined. Performing a short, one-day heater test reduces the estimation uncertainty of the most influential parameter (rock thermal conductivity) by a factor of three. Heater tests longer than about ten days provide only a minimal incremental reduction of uncertainty.

High salinity environments are advantageous for deep borehole disposal, because they imply prolonged isolation of the disposal zone from fresh recharge and greater density fluids that prevent the circulation of fluids to overlying aquifers. The next paper investigates the genesis of such brines, i.e., whether fluid-rock interactions (i.e., contact between granite and groundwater) can dehydrate subsurface waters and produce brines similar in composition to those observed at depth [6]. Such calculations aid in better constraining the conceptualisation of the deep rock environments that are deemed suitable for high-level waste disposal; confirming fluid-rock interactions on a multi-million-year timescale provides evidence of prolonged isolation of the disposal zone from fresh groundwater. Reaction path calculations in the PHREEQC computer programme are used to test whether potential dehydration or brine formation is caused by silicate hydrolysis. Calculations show that the same hydrous alteration minerals and ionic strengths resulted for groundwater and seawater starting fluids, suggesting that the granite hydrolysis reaction is relatively insensitive to the composition of the starting fluid. Calculations confirm that upon complete dissolution of the quartz from the granite, the final fluid ionic strength reaches values exceeding $6 \mathrm{~mol} / \mathrm{L}$, with only about $10 \%$ of the original volume of the fluid remaining. The calculations agree well with data from the Canadian Shield brines for ionic strength, $\mathrm{Ca} / \mathrm{Na}$ ratio and $\mathrm{Mg}$ concentrations.

A more traditional post-closure performance assessment study is undertaken for deep borehole disposal of Cs/Sr capsules in the third paper on this topic [7]. The study considers waste emplacement of $0.21-\mathrm{m}$-diameter waste packages in crystalline rock at a depth of about $5000 \mathrm{~m}$. The waste emplacement zone is $534 \mathrm{~m}$ deep, with a 2000-m-deep seal zone. Both zones are within the crystalline rock. No credit is taken for the carbon steel disposal packages during the calculations. The massively parallel non-isothermal multiphase flow and reactive transport code PFLOTRAN was used for the radionuclide mobilisation and transport calculations. The 2000-m seal zone has permeability (and porosity) values consistent with properties of bentonite clay (permeability of $\left.10^{-18} \mathrm{~m}^{2}\right)$, cement plugs $\left(10^{-18} \mathrm{~m}^{2}\right.$ ) and/or sand/crushed rock ballast $\left(10^{-14} \mathrm{~m}^{2}\right)$. Crystalline rock has a low permeability of $10^{-18} \mathrm{~m}^{2}$. The disturbed rock zone is $0.15-\mathrm{m}$-wide with a permeability of $10^{-16} \mathrm{~m}^{2}$. In addition to the deterministic nominal (or normal evolution) scenario, an additional scenario is evaluated in which a waste package is assumed to get stuck above the emplacement zone near a fracture that intersects the borehole. A case with and without flow in the fracture is considered. Results show that after $10 \mathrm{M}$ years, the ${ }^{135} \mathrm{Cs}$ (2.3 million years half-life) concentration $25 \mathrm{~m}$ above the emplacement zone is similar to the background concentration $\left(10^{-20} \mathrm{~mol} / \mathrm{L}\right)$. At approximately $20 \mathrm{~m}$ beyond the emplacement zone in the 
radial direction, the concentration is $10^{-15} \mathrm{~mol} / \mathrm{L}$ (about five orders of magnitude above the background concentration). For the nominal scenario, ${ }^{135} \mathrm{Cs}$ does not reach the biosphere. For the scenario with the stuck waste package and assuming a regional flow up-dip in the fracture, ${ }^{135} \mathrm{Cs}$ is transported approximately $200 \mathrm{~m}$ by advection but is still approximately $400 \mathrm{~m}$ below the sediments (for a 10-M-year simulation). Again, ${ }^{135} \mathrm{Cs}$ does not reach the biosphere within the simulation timeframe.

\subsection{Safety Cases}

Two safety cases are discussed: one for horizontal [8] and one for vertical [9] boreholes.

The horizontal borehole concept uses relatively small diameter holes that can be drilled with off-the-shelf equipment; the holes are cased and disposal sections backfilled [8]. This concept is deemed suitable for spent nuclear fuel and capsules with highly concentrated Cs/Sr from defence applications. For spent fuel disposal, disposal canisters up to $27 \mathrm{~cm}$ (BWR fuel) and $35 \mathrm{~cm}$ (PWR fuel) are considered, which would require borehole diameters of 40 and $48 \mathrm{~cm}$, respectively. Authors consider risks from the wire lines breaking during canister emplacement and canister contact impacts. For heavy disposal canisters, provisions can be made to reduce their velocity if the emplacement wires break, such as self-deploying braking devices, an expandable centraliser, a parachute mechanism or the use of foams. Collision damage can be mitigated by placing impact absorbers on the front end of the canister. Corrosion-resistant steel canisters based on nickel-chromium-molybdenum alloys [3] are proposed. The proposed carbon steel casings have an estimated lifetime of several hundred years, sufficient to restrict fluid flow during the early pressure equilibration and thermal periods. The rate at which hydrogen gas is generated from steel corrosion is sufficiently slow for the gas to dissolve in the fluid phase and diffuse in the host rock, thereby avoiding a free gas phase. All open spaces in the borehole were assumed backfilled with suitable materials, primarily cements. The vertical access hole was sealed and plugged. The horizontal section of the disposal hole should be sufficiently deep that the host rock pore space is saturated with brine. The paper cites the main advantages of borehole disposal over a conventional geological repository as fundamentally simpler to design, construct and operate and easier to demonstrate its short-term and long-term safety and its modularity. Differences between horizontal and vertical boreholes relate mainly to stratigraphy (a horizontal hole does not typically traverse zones with depth-dependent total stress, lithostatic and hydrostatic pressures, temperature and fluid density); vertical gradients; the mechanical load (potentially higher loads on canisters in a vertical hole, which could require a deeper disposal zone than a horizontal hole); drilling and waste emplacement.

The final paper presents key elements of the safety case for a vertical borehole [9]. For deep borehole disposal of high-level waste, these key elements are: safety strategy (i.e., strategies for management, siting and design and assessment); assessment basis (i.e., waste and engineered barriers, the geosphere/natural barriers and the biosphere and surface environment) and safety assessment (i.e., pre-closure safety analysis, a post-closure performance assessment and confidence enhancement analyses). The generic safety case is based on potential system designs, waste forms, engineering and geologic conditions without specific site information or regulatory framework. The generic borehole design features for the disposal of Cs/Sr capsules were previously discussed in [7]. Pre-closure assessment information includes effects of off-normal or disrupting events on pre-closure safety (e.g., dropping a waste package in the hole) and impacts of pre-closure activities on post-closure safety (e.g., efficacy of seals and plugs). The pre-closure safety assessment demonstrated that the probability of a successful borehole completion, a minimal or moderate incident and a potentially significant event was $95.4 \%, 4.6 \%$ and $0.0005 \%$, respectively. The post-closure safety assessments show that, for both the nominal and disturbed (stuck package) scenarios, there is minimal radionuclide migration away from the emplacement zone and zero dose for $10 \mathrm{M}$ years. Additional confidence enhancement information for post-closure safety includes: multibarrier design, low permeability and high sorption capacity of seal materials, geochemically reducing conditions at depth, the low permeability of crystalline host rock, density stratification of brine at depth, isolation and long residence time of deep groundwater and 
the great depth of disposal. To aid with the collection of key hydrogeological parameters, a preliminary borehole sampling and testing strategy was developed, with a focus on determining the chemical composition and salinity of deep fluids and the use of environmental tracers. The paper presents simulations demonstrating density stratification, vertical flow and mixing at depth under different conditions of hydraulic gradient and initial salinity. Simulations with a relatively high permeability show that by $1 \mathrm{M}$ years, the upper $1800 \mathrm{~m}$ of the model domain has been flushed with fresh water; circulation cells exist below that depth, with little mixing between the shallow fresh water and the deep brine. When a ten-times-lower permeability is used, only the upper $800 \mathrm{~m}$ of the domain has been flushed with fresh water, and isolated circulation cells have formed at depth. With a host rock permeability of $10^{-18} \mathrm{~m}^{2}$, advection does not develop in the deep basement brine; fluxes in the basement are three-to-four orders of magnitude smaller than fluxes in the sediments. Simulations also show that the salinity gradient limiting upward water flux is persistent. Finally, proper borehole sealing is pivotal to a safe borehole disposal concept. Sealing materials discussed include cements, clay-based systems, geopolymers, silicone rubber, asphalt, crushed rock, ceramic seals and rock welding.

\section{Conclusions}

A comprehensive overview of the state-of-the-science and technology of deep borehole disposal was captured in this Special Issue. Contributions from nine journal papers covered topics on waste types, engineered barrier performance, performance assessments and the safety case. This provides a sufficient knowledge base to plan and execute field-based demonstration projects that address key elements of borehole disposal, including deep drilling of wide-diameter holes, waste emplacement testing and seal emplacement and performance monitoring.

Author Contributions: Conceptualisation, D.M.; writing - original draft preparation, D.M. and writing-review and editing, K.T., P.V.B., N.C. and H.G. All authors have read and agreed to the published version of the manuscript.

Funding: This research received no external funding.

Conflicts of Interest: The authors declare no conflicts of interest.

\section{References}

1. Chapman, N.A. Who Might Be Interested in a Deep Borehole Disposal Facility for Their Radioactive Waste? Energies 2019, 12, 1542. [CrossRef]

2. Bracke, G.; Kudla, W.; Rosenzweig, T. Status of Deep Borehole Disposal of High-Level Radioactive Waste in Germany. Energies 2019, 12, 2580. [CrossRef]

3. Payer, J.H.; Finsterle, S.; Apps, J.A.; Muller, R.A. Corrosion Performance of Engineered Barrier System in Deep Horizontal Drillholes. Energies 2019, 12, 1491. [CrossRef]

4. Collier, N.C.; Milestone, N.B.; Travis, K.P. A Review of Potential Cementing Systems for Sealing and Support Matrices in Deep Borehole Disposal of Radioactive Waste. Energies 2019, 12, 2393. [CrossRef]

5. Finsterle, S.; Muller, R.A.; Baltzer, R.; Payer, J.; Rector, J.W. Thermal Evolution near Heat-Generating Nuclear Waste Canisters Disposed in Horizontal Drillholes. Energies 2019, 12, 596. [CrossRef]

6. Brady, V.P.; Lopez, C.; Sassani, D. Granite Hydrolysis to Form Deep Brines. Energies 2019, 12, 2180. [CrossRef]

7. Freeze, G.A.; Stein, E.; Brady, P.V. Post-Closure Performance Assessment for Deep Borehole Disposal of Cs/Sr Capsules. Energies 2019, 12, 1980. [CrossRef]

8. Muller, R.A.; Finsterle, S.; Grimsich, J.; Baltzer, R.; Muller, E.A.; Rector, J.W.; Payer, J.; Apps, J. Disposal of High-Level Nuclear Waste in Deep Horizontal Drillholes. Energies 2019, 12, 2052. [CrossRef]

9. Freeze, G.A.; Stein, E.; Brady, P.V.; Lopez, C.; Sassani, D.; Travis, K.; Gibb, F.; Beswick, J. Deep Borehole Disposal Safety Case. Energies 2019, 12, 2141. [CrossRef] 